\title{
Seismic Behavior of Reinforced Concrete Members Built with Recycled Aggregate
}

\author{
${ }^{1}$ Alper Ilki, ${ }^{* 2}$ Ilyas Saribas and ${ }^{1}$ Caglar Goksu \\ ${ }^{1}$ Civil Engineering Faculty, Istanbul Technical University, Istanbul, Turkey \\ *2Faculty of Engineering, Department of Civil Engineering, AAT Science and Technology University, Turkey
}

\begin{abstract}
:
In connection with rapid urbanization and earthquakes, a huge number of structures have been demolished and generated lots of waste concrete for the last 40 years. Studies on the reclamation of the waste concrete is a pioneer subject for construction sectors in the world. Since the recycling of the waste concrete and reusing of recycled concrete aggregate in the production of new concrete is an important issue for saving of natural resources, economic, sustainable development, significant number of studies have been carried out on this subject. In the scope of this study, a literature review is conducted on the effect of recycled concrete aggregate on mechanical and durability characteristics of small-scale members. Furthermore, structural and seismic performances of full-scale reinforced concrete structural members produced with recycled concrete aggregate are discussed. The test results indicated that the structural members containing recycled aggregate exhibited similar structural performance with their counterparts containing natural aggregates. It was also observed that recycled concrete aggregate did not seem to have an adverse effect on seismic characteristics of the structural members such as ductility.
\end{abstract}

Key words: Column, Recycled aggregate, Reinforced concrete, Seismic, Slab, Waste concrete.

\section{Introduction}

Protecting of natural aggregate (NA) resources has been an important subject in the world for finding sustainable solution after the first and second World Wars. After the wars, construction process in the world continued to increase both to satisfy an enormous demand for building materials and to clean out the building demolition waste from the demolished cities. Recycling the aggregates obtained from the demolished buildings gave chance not only to reduce site clearing costs, but also to satisfy the demand of construction materials for the new construction. Recently, the increasing of population and urbanization in the countries has led to construction of new structures. Moreover, the existing structures, which reach the end of their service life and are inconvenient for the modified seismic codes, has to be demolished. Recycled concrete aggregate (RCA) appears to be an important alternative in response to growing environmental, social and economic problems.

Therefore, significant number of experimental studies have been performed for the last 40 years for the safely utilization of RCA in new concrete construction. Most of the studies concentrated on material characteristics of RCA, and mechanical and durability characteristics of recycled aggregate concrete (RAC) [1-9]. While there is significant number of studies about safely utilization of RCA in new concrete applications in the literature [10-26], there is a lack of experimental and analytical study on the structural performance of structural members incorporating RAC, particularly on seismic performance of these members. In order to fulfill this 
gap, a comprehensive experimental study, in which the full-scale structural members such as reinforced concrete (RC) slabs and columns were tested for investigating the effect of inclusion of low-quality (sourced from low strength concrete) RCA on bending, flexure and shear performances of these structural members, was conducted. In this paper, test results of these structural members are discussed. Furthermore, the changes in mechanical and durability properties due to usage of RAC in concrete mix are summarized in the following section.

\section{Literature Review}

In this section, the mechanical properties of RAC related with the compressive strength, modulus of elasticity, splitting tensile strength, flexural strength and durability properties of the concrete obtained from the literature are presented as a summary.

Based on the existing knowledge in literature (more than 240 detailed studies), which were conducted on the influence of the water-to-binder ratio, aggregate to-cement ratio, RCA replacement ratio, parent concrete strength, adhered mortar content and particle size of RCA, moisture state of RCA, RAC density, mixing method, curing condition, chemical admixture, pretreatment of RCA, and mineral admixture on the compressive strength of RAC, and the authors' previous studies on this subject, the concrete compressive strength decreased with the increase in incorporation of RCA. The decrease (between 10\% to 30\%) in concrete compressive strength may be explained with the higher absorption capacity of RCA than NA, poor interfacial transition zones (ITZ) between RCA and cement [22, 27-30].

The modulus of elasticity is an important mechanical parameter to describe the stiffness of the concrete. According to the previous researches conducted on the modulus of elasticity of RAC, depending on general characteristic structure of RCA (porous texture, lower stiffness of attached mortar), the modulus of elasticity of RAC was found to be lower than that of natural aggregate concrete (NAC). It is stated in these studies that depending on the ratio of RCA, this decreasing ratio of modulus of elasticity of RAC may be between $20 \%$ to $45 \%$ [27-30].

According to the literature, increasing in RCA ratios in new concrete led to the reduction (between $10 \%$ to $25 \%$ ) in splitting tensile and flexural strengths of RAC. The reduction in the splitting tensile and flexural strengths of RAC can be explained with the lower tensile strength of RCA than that of NA [27-30]. Furthermore, while the bond strength between RAC and plain rebar decreases (up to $12 \%$ ) with increasing of RCA ratio in new concrete, the bond strength between the RAC and the deformed steel rebar is obtained to be similar to NAC and the deformed steel rebar regardless from RCA ratio in concrete mix [22, 27-30].

Due to the structure of RCA (higher porosity, higher water absorption capacity, lower aggregate interlock capacity than NA), the durability performance of RAC is generally obtained to be lower than that of NAC [27-28].

\section{Full-Scale Tests on RC Slabs and Columns}

The reported study in this paper is a part of a comprehensive experimental study in which twelve $\mathrm{RC}$ slabs and fourteen RC columns were produced and tested for investigating the effect of 
inclusion of low-quality RCA on bending, flexure and shear performances of these structural members. Before seismic tests, as a first step, to determine the structural behavior only under bending, RC slabs were subjected to three-point bending test under monotonic increasing deflections. The other reasons for selecting the slabs as test specimens are (1) The amount of concrete used in casting of slabs is much higher compared to columns and beams in practice. Therefore, in case the utilization of RCA in construction of slabs becomes mainstream, there would be a prompt reduction in the waste material storage. (2) The concrete strength has only minor influence on the load-bearing capacity of flexural members, which are not subjected to axial forces. In literature, there are few studies on slabs incorporating RCA [31-36]. Among these studies, research on flexural behavior of slabs is scarce [35-36] and do not cover the tests of members constructed using RCA sourced from low strength concrete. On the other hand, although there are numerous studies related to utilization of RCA in new concrete applications, little information has been reported on the seismic performance of RC columns constructed of recycled aggregate concrete (RAC) [23-26]. The studies of Xiao et al. [24], in which semi-precast columns were evaluated, and Ma et al. [25-26], in which composite columns were evaluated, it was reported that the lateral load and deformation capacities of RAC columns trended lower than those of NAC columns as the replacement ratio of RCA increased. Soleimani et al. [23] studied the seismic responses of code-complying and non-code complying RC columns made of NAC and RAC under a fixed axial load set at $10 \%$ of the axial load capacity of the column and reported that RAC columns exhibited structural behavior similar to columns constructed of NAC. Therefore, in the study by the authors, seismic tests on eight RC columns were conducted to quantify the effects of different axial loads, which covers a wide range of axial loading $(7 \%, 17 \%, 27 \%$, and $37 \%$ of the axial load capacity of the column), on the seismic performance of RC columns incorporating RCA sourced from low strength concrete waste. In addition to that seismic tests on six RC columns were also conducted to investigate the shear behavior of the columns after flexure reinforcement yielding.

\subsection{Material tests}

In the scope of the studies by the authors, the RCA was obtained from typical structural members, which have concrete compressive strength ranged from $7 \mathrm{MPa}$ to $16 \mathrm{MPa}$. The tests for particle density, organic impurities, methylene blue, soluble acid sulphates, ASR, chloride content, alkali content, water absorption, and Los Angeles abrasion were then conducted to determine the fundamental characteristics of the RCA. Table 1 summarizes the test results of the NA and RCA used in this research. Notably, while the particle density, organic impurities, methylene blue, soluble acid sulphates, ASR, chloride, and alkali content of the RCA are similar to that of the NA, the water absorption and Los Angeles abrasion of the RCA are significantly higher than those of the NA due to the adhered mortar content of the RCA. Based on the material test results, it is concluded that the RCA can be used in the production of RAC. 
Table 1. Basic properties of NA and RCA

\begin{tabular}{|c|c|c|c|c|c|c|}
\hline \multirow[b]{2}{*}{ Aggregate tests } & \multirow[b]{2}{*}{ Unit } & \multicolumn{4}{|c|}{ NA } & \multirow{2}{*}{$\frac{\mathrm{RCA}}{5-12 \mathrm{~mm}}$} \\
\hline & & $\begin{array}{c}\text { Mountain sand } \\
0-2 \mathrm{~mm}\end{array}$ & $\begin{array}{c}\text { Crushed sand } \\
0-4 \mathrm{~mm}\end{array}$ & $\begin{array}{c}\text { No } 1 \text { aggregate } \\
5-12 \mathrm{~mm}\end{array}$ & $\begin{array}{c}\text { No } 2 \text { aggregate } \\
12-22 \mathrm{~mm}\end{array}$ & \\
\hline Water absorp. & $\%$ & 1.8 & 0.9 & 0.6 & 0.4 & 3.5 \\
\hline Particle density & $\mathrm{g} / \mathrm{cm}^{3}$ & 2.53 & 2.7 & 2.7 & 2.72 & 2.61 \\
\hline Los Angeles abr. & $\%$ & - & - & 21 & 21 & 36 \\
\hline Org. impurities & - & Lighter & Lighter & Lighter & Lighter & Lighter \\
\hline Methylene blue & $\%$ & 0.5 & $<1$ & 0.5 & - & 0.75 \\
\hline Acid sol. sulp. & $\%$ & 0.05 & 0.19 & 0.09 & 0.07 & 0.41 \\
\hline ASR & $\%$ & 0.2 & 0.06 & 0.07 & 0.06 & 0.18 \\
\hline Chloride cont. & $\%$ & 0.02 & $<0.001$ & $<0.001$ & $<0.001$ & $<0.001$ \\
\hline Alkali cont. & $\%$ & 0.04 & $<0.01$ & $<0.01$ & $<0.01$ & $<0.01$ \\
\hline Moisture cont. & $\%$ & 0.0173 & 0.0087 & 0.0081 & 0.0066 & 0.007 \\
\hline
\end{tabular}

absorp.: absorption; abr.: abrasion; org.: organic; ASR: alkali-silica reactivity; sol. sulp.: soluble sulphates; cont.: content

Four different concrete mixtures (M-R0 mix is with 100\% NA, M-R50 mix is with substitution of $50 \%$ of the coarse RCA, M-R0-PZ mix is with $100 \%$ NA and $15 \%$ fly ash, M-R50-PZ mix is with substitution of $50 \%$ of the coarse RCA and $15 \%$ fly ash) were used to produce RC slabs (Table 2). On the other hand, two concrete mix-proportions (RAC and NAC) were prepared for RC columns (Table 2). For the concrete mixes incorporating RCA, approximately $50 \%$ by weight of the midsized coarse NA was replaced by RCA for the concrete mix-proportion. Recycled aggregate is generally used as 10-35\% replacement of coarse aggregate in the production of structural concrete $[22,29]$. In this study, No1 type NA was completely replaced by RCA, which approximately corresponds to $50 \%$ replacement of the coarse aggregates. Although this ratio is higher than the currently suggested limits, it allowed to investigate the structural behavior of the RC members with higher RCA replacement ratios. The compressive strengths of the concrete mixes of the slabs and columns were obtained based on the tests on cylinder specimens $(150 \mathrm{~mm} \times 300 \mathrm{~mm})$, and presented in Figures 1 and 2, respectively. Based on the average test results, the concrete compressive strengths decreased with the incorporation of RCA. The decrease in concrete compressive strengths of the group M-R50 with respect to the group M-R0 was $18 \%$. The test results also revealed that partial replacement of cement with fly ash caused a decrease in concrete compressive strengths. The decrease in the concrete compressive strength of group M-R0-PZ with respect to the group M$\mathrm{R} 0$ was $20 \%$. The decrease in the concrete compressive strength of group M-R50-PZ with respect to group M-R50 was $17 \%$.

The slump values of the NAC and RAC mixes were determined to be around $18-22 \mathrm{~cm}$. It should be noted that for the real simulation of RC column in theoretical calculations, the compressive strengths of drilled core specimens taken from the RC columns were used by converting the obtained core strengths to standard cylinder compressive strengths based on the recommendations of the Concrete Society [37] and BS 6089 [38]. The average standard cylinder compressive strengths of NAC and RAC were determined to be $35 \mathrm{MPa}$ and $29 \mathrm{MPa}$, respectively. There was still an approximately $17 \%$ difference in the concrete compressive strengths of the NAC and RAC columns. This can be attributed to the higher absorption capacity and poor interfacial transition zones between RCA and cement, as also previously reported by Xie et al. [28]. 

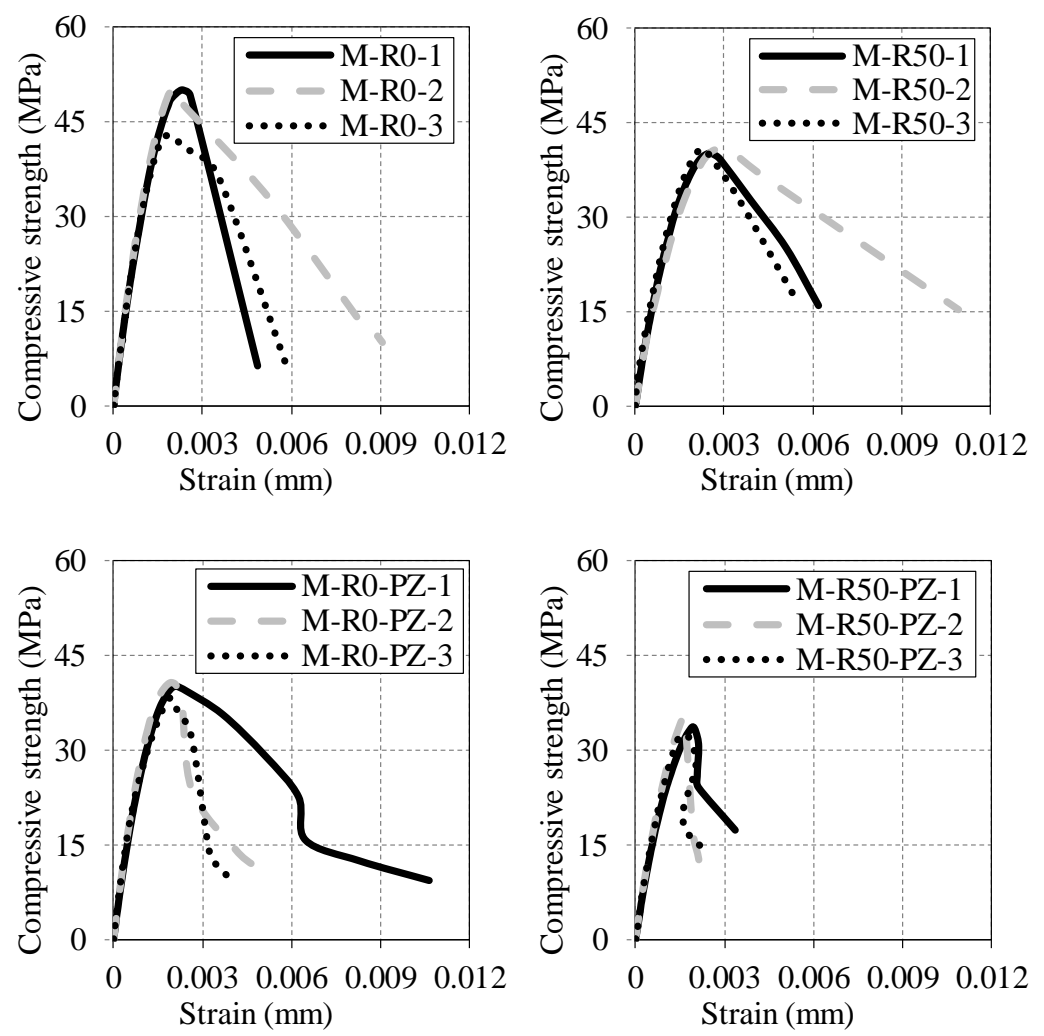

Figure 1. Compressive stress-strain relationships of the specimens

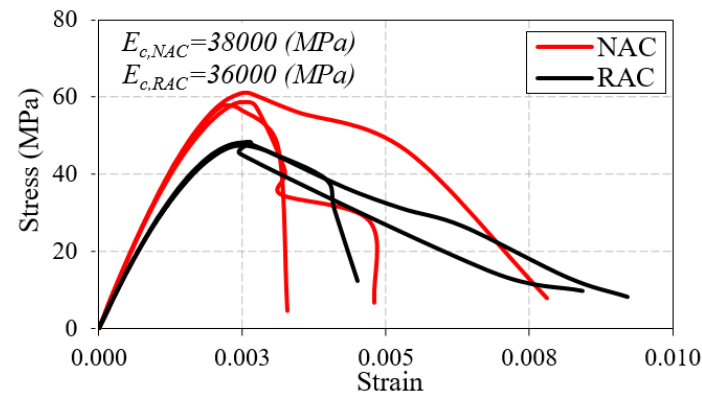

Figure 2. Stress-strain relationships of cylinder specimens

Table 2. Concrete mix-proportions

\begin{tabular}{l|c|c|c|c|c|c}
\hline \hline Material quantity $\left(\mathrm{kg} / \mathrm{m}^{3}\right)$ & M-R0 & M-R50 & M-R0-PZ & M-R50-PZ & NAC & RAC \\
\hline NA-No 2 aggregate (10-20 mm) & 489 & 493 & 472 & 472 & 489 & 493 \\
\hline NA-No 1 aggregate (5-12 mm) & 501 & - & 484 & - & 501 & - \\
\hline RCA (5-12 mm) & - & 522 & - & 500 & - & 522 \\
\hline Crushed sand (washed) (0-4 mm) & 407 & 410 & 393 & 393 & 407 & 410 \\
\hline Sand (0-2 mm) & 513 & 518 & 495 & 495 & 513 & 518 \\
\hline Fly ash (Class F) & - & - & 50 & 50 & - & - \\
\hline Cement (CEM 42.5 R) & 300 & 300 & 270 & 270 & 300 & 300 \\
\hline Water (lt) & 128 & 110 & 142 & 131 & 128 & 110 \\
\hline Superplasticizer (Glenium ACE 450) (lt) & 1.95 & 2.1 & 2.24 & 2.24 & 1.95 & 2.1 \\
\hline Water/cement & 0.43 & 0.37 & 0.49 & 0.45 & 0.43 & 0.37 \\
\hline \hline
\end{tabular}




\subsection{Details of the specimens}

The cross-sectional dimensions of full-scale one-way RC slabs were $2800 \mathrm{~mm} \times 600 \mathrm{~mm} \times 120 \mathrm{~mm}$. The longitudinal reinforcement of the slabs consisted of $8 \mathrm{~mm}$ deformed steel (B420C) reinforcing bars. The thickness of the concrete clear cover is $26 \mathrm{~mm}$ for the slabs.

Eight out of fourteen RC columns in the experimental campaign, which were tested to determine the effect of axial load on seismic behavior, were designated as NAC-7-s60, RAC-7-s60, NAC-17s60, RAC-17-s60, NAC-27-s60, RAC-27-s60, NAC-37-s60, RAC-37-s60. The first term, "NAC" represents natural aggregate concrete and "RAC" represents recycled aggregate concrete, the second term indicates the axial load, and the third term indicates the spacing between the transverse reinforcing bars. Hence, the specimen name "NAC-7-s60" indicates a column incorporating NAC tested at $7 \%$ of the axial load capacity of the column with a transverse reinforcement spacing of 60 $\mathrm{mm}$. The heights of these columns were $1500 \mathrm{~mm}$. Shear span-to-depth ratio $(\mathrm{a} / \mathrm{d})$ of these specimens was 4.65. The spacings of transverse reinforcement were selected as $60 \mathrm{~mm}$. These columns were exposed to $7 \%, 17 \%, 27 \%$ and $37 \%$ of the axial load capacity of columns without consideration of the capacity of the internal steel reinforcement. It should be noted that the axial load ratios $7 \%, 17 \%, 27 \%$ and $37 \%$ (hereafter $0.07 P_{0}, 0.17 P_{0}$, and $0.27 P_{0}, 0.37 P_{0}$ ) were selected to represent very low, low, moderate and high axial load ratios used in practical applications. The rest of the columns (six out of fourteen columns), which were tested to investigate the shear behavior after yielding of longitudinal reinforcement, were designated as NAC-s100, RAC-s100, NAC-s150, RAC-s150, NAC-s200, RAC-s200. The first term indicates the concrete type (NAC or RAC) while the second term indicates the spacing between the transverse reinforcing bars (100 $\mathrm{mm}$ or $150 \mathrm{~mm}$ or $200 \mathrm{~mm}$ ). The heights of these columns were $900 \mathrm{~mm}$. Shear span-to-depth ratio (a/d) of these specimens was 2.35 . The columns were exposed to $30 \%$ of the axial load capacity of columns without consideration of the longitudinal reinforcement. For all columns, the crosssectional dimensions were $300 \times 300 \mathrm{~mm}$, the geometric ratio of longitudinal reinforcement was $1.13 \%$, the thickness of the concrete clear cover over the transverse reinforcement was $21 \mathrm{~mm}$. The longitudinal and transverse reinforcement of columns consisted of $18 \mathrm{~mm}$ and $10 \mathrm{~mm}$ deformed steel reinforcing bars, respectively.

\subsection{Test setup and loading procedure}

Three-point bending test setup were used for testing of the slabs (Figure 3a). The LVDTs were installed at mid-span at supports to measure the displacements at these points. The strain gages were also installed on the longitudinal reinforcing bars at the mid-span for observing the variations in strains during the test [22].

The columns tested in this study were subjected to constant axial and cyclically reversing lateral loads (Figure 3b). Two different displacement-based lateral loading procedures were used for the columns. Reversing lateral displacements were applied to the columns in pushing and pulling cycles to simulate seismic loading. To measure the strains and the displacements during the loadings, strain gages and linear variable differential transducers (LVDTs) were used for all columns, respectively [29-30]. 


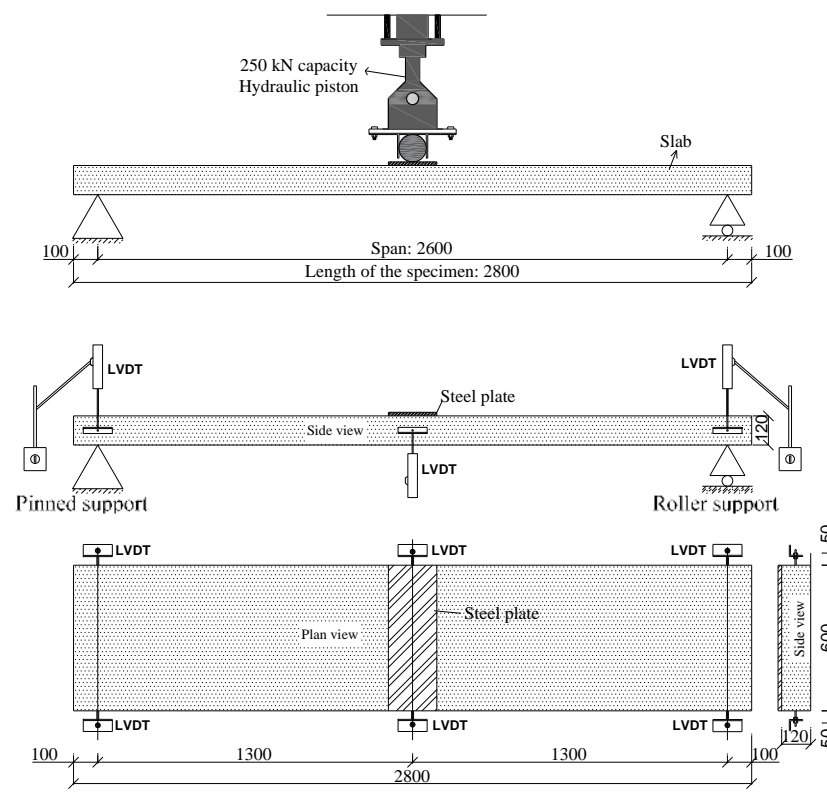

(a)

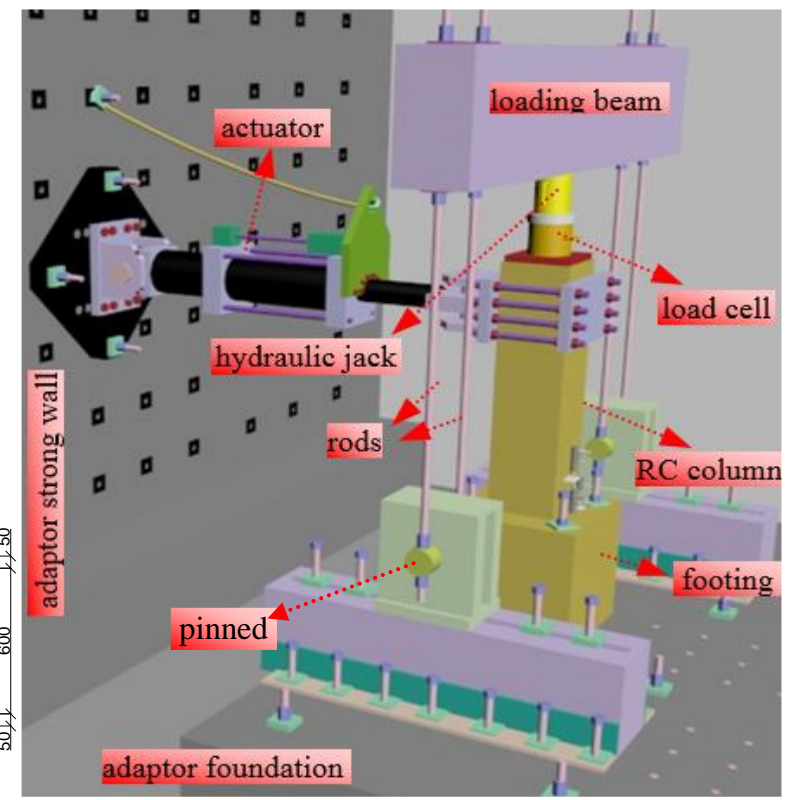

(b)

Figure 3. Test setups; (a) for the slabs, (b) for the columns (Dimensions are in mm)

\subsection{Test results}

The envelopes of the load-displacement relationships of the RC slabs are presented in Figure 4. As seen in this figure, the slabs produced with RCA without fly ash showed the lowest load bearing capacity among their counterparts, while the slabs produced with only NA showed the highest load bearing capacity. Furthermore, while there was marginal difference in load carrying capacities of all slabs, the deformation capacities and damage states of the slabs were similar regardless of concrete type. The main flexural cracks were observed at the mid span of the slabs. The tests of the slabs ended with the rupture of longitudinal reinforcing bars in the mid span for all RC slabs. No concrete crushing was observed at the compression zone. It should also be noted that the conventional RC theory remains valid for the slabs incorporation RCA sourced from low strength concrete [22].

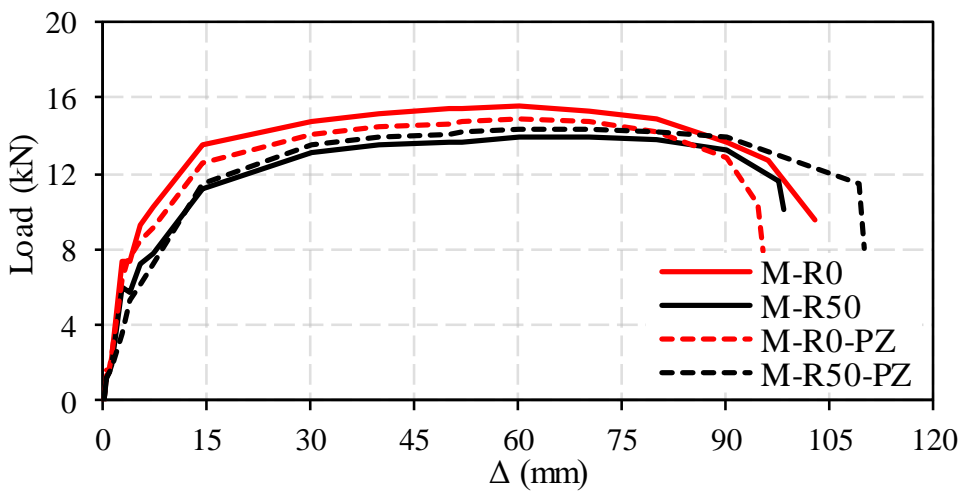

Figure 4. Average load-displacement curves of the RC slabs 
The envelopes of load-displacement curves of the columns, which had ald ratio of 4.65, are shown in Figure 5. For better evaluation of the seismic behavior of the columns, the experimental lateral loads were normalized with the theoretical lateral, which is calculated based on the momentcurvature relationships at the critical section of the columns based on fiber analysis approach. The details of the theoretical study can be found in the study of Saribas [29] and Saribas et al. [30]. All columns presented flexural behavior and failed in flexure. As seen in this figure, the lateral load capacities of the companion columns are similar. No cracking was observed up to $0.5 \%$ drift ratio. As the drift ratio increased, fine bending cracks increased gradually along the plastic hinge region of the columns. When the drift ratio increased up to $4 \%$ drift ratio, the flexural bending cracks of the columns widened and lengthened gradually.
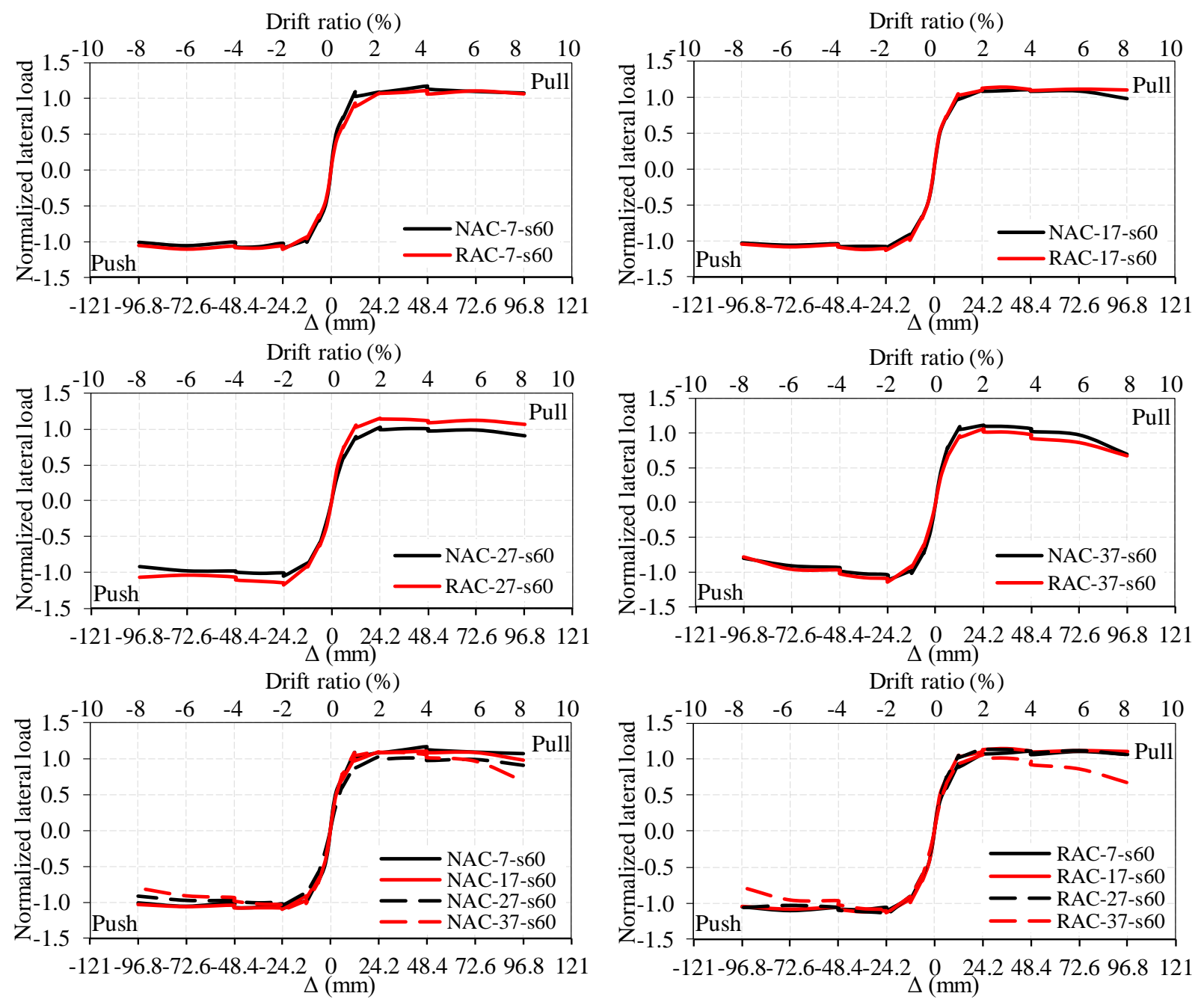

Drift ratio $(\%)$

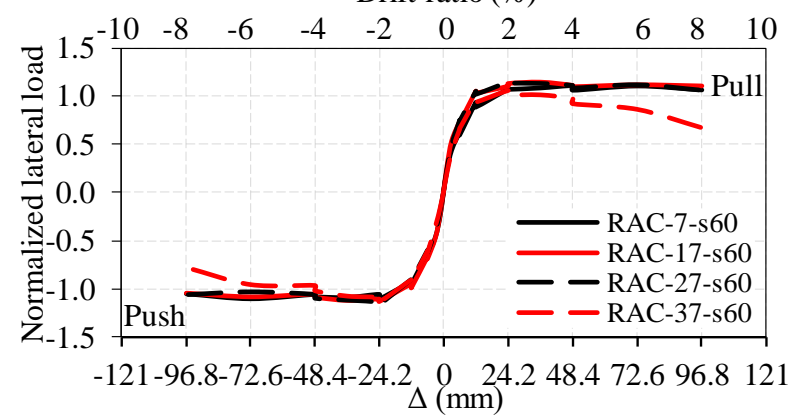

Figure 5. Normalized envelopes of lateral load-displacement relationships of the columns

Crushing of concrete cover initiated in compression zone between the 3\%-4\% drift ratios for the columns subjected to $0.07 P_{0}, 2 \%$ drift ratio for the columns subjected to $0.17 P_{0}$ and $0.27 P_{0}$, and at $1 \%$ drift ratio for the columns subjected to $0.37 P_{0}$ regardless from the concrete type. It should also 
be noted that while the columns subjected to $0.07 P_{0}, 0.17 P_{0}$ and $0.27 P_{0}$ sustained their lateral load up to the end of test ( $8 \% \mathrm{drift}$ ratio), the lateral load degradation of the column subjected to $0.37 P_{0}$ was observed after the peak strength at $2 \%$ drift ratio. Furthermore, while the crushing of the concrete cover started after the yielding of longitudinal reinforcing bars of these columns subjected to $0.07 P_{0}, 0.17 P_{0}$ and $0.27 P_{0}$, the crushing of the concrete cover started before the yielding of longitudinal reinforcing bars of the columns subjected to $0.37 P_{0}$ regardless of the concrete type. At the end of the test, buckling of longitudinal reinforcement were observed only at the test region of columns subjected to $0.37 P_{0}[29,30]$. Furthermore, the lateral load capacities increased as the axial load increased for either NAC or RAC columns because at higher axial loads, a higher proportion of concrete is subjected to compressive stress, and therefore a higher proportion actively participates in resisting the effects of the flexural load.

The normalized lateral load capacities and displacement ductility factors for the columns, which had ald ratio 2.35, are given in Table 3. These columns reached their peak lateral load at and around $2 \%$ drift ratio. At this drift ratio, while there are marginal differences between the lateral load capacities, the capacities of the columns are similar regardless of amount of transverse reinforcement. The displacement ductility factors $\left(\mu_{\Delta}\right)$, the ratio of the ultimate displacement $\left(\Delta_{u}\right)$ to the yield displacement $\left(\Delta_{y}\right)$, are calculated and listed in Table 3. As seen in this table, the ductility ratio decreases with decrease in the amount of transverse reinforcement bars regardless of concrete type.

Table 3. Normalized lateral load capacity and displacement ductility factors for the columns,

which had a/d ratio 2.35

\begin{tabular}{c|c|c|c|c}
\hline \hline Specimens & $\begin{array}{c}\text { Normalized lateral load } \\
\text { capacity }\end{array}$ & $\Delta_{y}(\mathrm{~mm})$ & $\Delta_{u}(\mathrm{~mm})$ & $\mu_{\Delta}$ \\
\hline NAC-s100 & 1.07 & 7.9 & 45 & 5.7 \\
\hline RAC-s100 & 1.11 & 7.9 & 44 & 5.6 \\
\hline NAC-s150 & 1.01 & 9.9 & 26.4 & 2.7 \\
\hline RAC-s150 & 1.13 & 9.9 & 32 & 3.2 \\
\hline NAC-s200 & 1.1 & 11.9 & 26 & 2.2 \\
\hline RAC-s200 & 1.25 & 11.9 & 26 & 2.2 \\
\hline \hline
\end{tabular}

In the light of the literature and the studies by the authors, it is concluded that columns made of RCA are able to resist seismic actions if they are properly designed and constructed. To encourage the use of RCA worldwide, it is also critical to assure its behavior under extreme conditions, one of those is structural fire endurance. There is only limited number of studies on the performance of RCA when subjected to elevated temperatures [39-44]. These studies except the study by Dong et al. [43] were carried out on small scale cylinder specimens, and reported the hardened properties of concrete such as compressive strength, splitting tensile strength, modulus of elasticity. The study by Dong et al. [43] was carried out on full-scale column specimens $(450 \times 450 \mathrm{~mm}$ in cross-section and $3640 \mathrm{~mm}$ in height) and fire resistance performance of these columns were investigated. According to these studies, it was reported that thermal characteristics and residual mechanical properties were found to be roughly similar to that of exhibited by NA. Among these studies, the post-fire seismic behavior of cast-in-place reinforced concrete (RC) columns has not been considered so far. To fulfil this gap, an experimental study is conducted to investigate the seismic performance of columns made with RCA with a particular focus on the effect of fire exposure duration. The details of this work will be published separately Unal et al. [45]. 


\section{Conclusions}

This paper presents the results of a comprehensive experimental study conducted on full-scale twelve RC slabs and fourteen RC columns. While eight out of fourteen RC columns were tested to determine the effect of axial load on seismic behavior, which had ald ratio 4.65, the rest of the columns were tested to investigate the shear behavior after yielding of longitudinal reinforcement, which had a/d ratio 2.35. One identical specimen from each group was constructed using NA to serve as reference specimens. All test results revealed that the structural and seismic indicators of these members produced with RAC were similar to the NAC. Moreover, while there was a slight difference in bending moment capacities of all slabs, the damage states of the slabs were similar regardless of concrete type. For the RC columns, which had ald ratio 4.65, the columns subjected to $0.07 P_{0}, 0.17 P_{0}, 0.27 P_{0}$ exhibited ductile behavior until the end of the tests, a remarkable strength reduction after the peak strength was observed for the columns subjected to $0.37 P_{0}$ due to occurrence of crushing of concrete before yielding of longitudinal reinforcing bars regardless of concrete type. For the RC columns, which had a/d ratio 2.35, the amount of transverse reinforcement had a significant effect on ductility parameters of the columns that the ductility ratio decreases with the decrease in the amount of transverse reinforcement regardless of concrete type. It can be concluded from the results that RCA did not seem to have an adverse effect on the bending, flexural and shear behavior of the RC members. This observation is valuable for demonstrating that RCA can be safely utilized in structural concrete. It should be emphasized that all findings are valid for the ranges of the parameters tested within this study. For reaching more general conclusions on the use of RCA in the production of new RC structures, there is an obvious need for further studies.

\section{Acknowledgement}

The supports of Yapı Merkezi and Akçansa Companies, the contributions of staff of ITU Structural and Earthquake Engineering Laboratory, financial supports of ITU Scientific Research Department (Project No: 39360) and The Scientific and Technological Research Council of Turkey (Project No: 115M029) are gratefully acknowledged.

\section{References}

[1] Buck A D. Recycled concrete as a source of aggregate. ACI J. 1977; 74(5): 212-219.

[2] Khan A. Recycled concrete-a source for new aggregate. Cem. Concr. Agg. 1984; 6(1):17-27.

[3] Hansen T C, Boegh E. Elasticity and drying shrinkage of RAC. ACI J. 1985; 82(5):648-652.

[4] Tavakoli M, Soroushian P. Strength of RAC made from field-demolition aggregate. ACI Mat. 1996; 93:178-191.

[5] Topcu I B, Sengel S. Properties of concretes produced with waste concrete aggregate. Cem. Conc. Res. 2004; 34(8):1307-1312.

[6] Kou S C, Poon C S, Chan D. Influence of fly ash as a cement addition on the hardened properties of RAC. Mat. Struct. 2008; 41(7):1191-1201. 
[7] Malešev M, Radonjanin V, Marinkovic S. Recycled concrete as aggregate for structural concrete production. Sustainability 2010; 2(5):1204-1225.

[8] Dabhade A N, Choudhari S R, Gajbhiye A R. Performance evaluation of RA used in concrete. Int. J. Eng. Res. Appl. 2012; 2:1387-1391.

[9] Choi H, Lim M, Inoue M, Kitagaki R, Noguchi T. Evaluation on the mechanical performance of low-quality RA through interface enhancement between cement matrix and coarse aggregate by surface modification technology. Int. J. Conc. Struct. Mat. 2016; 10(1):87-97.

[10] Han B C, Yun H D, Chung S Y. Shear capacity of reinforced concrete beams made with recycled-aggregate. ACI J. Spec. Pub. 2001; 200:503-516.

[11] Corinaldesi V, Moriconi G. Behavior of beam-column joints made of sustainable concrete under cyclic loading. J. Mat. Civ. Eng. 2006; 18(5):650-658.

[12] Xiao J, Falkner H. Bond behavior between RAC and steel rebars. Constr. Build. Mat. 2007; 21(2):395-401.

[13] Choi H B M, Kang K L. Bond behavior of deformed bars embedded in RAC. Mag. Conc. Res. 2006; 60(6):399-410.

[14] Gonzalez-Fonteboa B, Martinez-Abella F, Martinez-Lage I, Eiras-Lopez J. Structural shear behavior of recycled concrete with silica fume. Constr. Build. Mat. 2009; 23(11):3406-3410.

[15] Fathifazl G, Razaqpur A G, Abbas A B, Fournier B, Foo S. Shear capacity evaluation of steel reinforced recycled concrete (RRC) beams without stirrups. Eng. Struct. 2011; 33(3):1025-1033.

[16] Schubert S, Hoffmann C, Leemann A, Moser K, Motavalli M. RAC: experimental shear resistance of slabs without shear reinforcement. Eng. Struct. 2012; 41:490-497.

[17] Sindy S P, Belen G F, Javier E L. Bond behavior of steel reinforcement and recycled concrete. Mat. Struct. 2013; 47:323-334.

[18] Kim S W, Yun H D. Evaluation of the bond behavior of steel reinforcing bars in recycled fine aggregate concrete. Cem. Concr. Comp. 2014; 46:8-18.

[19] Zhang J, Cao W, Meng S, Yu C, Dong H. Shaking table experimental study of recycled concrete frame-shear wall structures. Earth. Eng. Vib. 2014; 13(2):257-267.

[20] Rise N, De Brito J, Correia J R, Arruda M R T. Punching behavior of concrete slabs incorporating coarse recycled concrete aggregates. Eng. Struct. 2015; 100:238-248.

[21] Pacheco J, De Brito J, Ferreira J, Soares D. Flexural load tests of full-scale RAs concrete structures. Constr. Build. Mat. 2015; 101:65-71.

[22] Goksu C, Saribas I, Binbir E, Akkaya Y and Ilki A. Structural performance of recycled aggregates concrete sourced from low strength concrete. Structural Engineering and Mechanics, 2019; 69(1):77-93.

[23] Soleimani F, McKay M, Yang C S W, Kurtis K E, DesRoches R, and Kahn L F. Cyclic testing and assessment of columns containing recycled concrete debris. ACI J. 2016; 113(5):1009-1020.

[24] Xiao J, Huang X, Shen L. Seismic behavior of semi-precast column with recycled aggregate concrete. Const. Build. Mat. 2012; 35:988-1001.

[25] Ma H, Xue J, Luo D, Zhang X. Seismic performance of steel-reinforced recycled concrete columns under low cyclic loads. Const. Build. Mat. 2013; 48:229-237.

[26] Ma H, Xue J, Liu Y, Zhang X. Cyclic loading tests and shear strength of steel reinforced recycled concrete short columns. Eng. Struct. 2015; 92:55-68.

[27] Xiao J. Recycled aggregate concrete structures. Springer Tracts in Civil Engineering, 2018, https://doi.org/10.1007/978-3-662-53987-3. 
[28] Xie T, Gholampour A and Ozbakkaloglu T. Toward the development of sustainable concretes with recycled concrete aggregates: comprehensive review of studies on mechanical properties. J. Mater. Civ. Eng., 2018, DOI: 10.1061/(ASCE)MT.1943-5533.0002304.

[29] Saribas I. Use of environmental friendly recycled aggregate concrete in production of structural members, PhD. Thesis (2018), Graduate School of Science, Engineering and Technology, Istanbul Technical University.

[30] Saribas I, Goksu C, Binbir E, Ilki A. Seismic performance of full-scale RC columns containing high proportion recycled aggregate. Bull. Earthquake Eng. 2019; https://doi.org/10.1007/s10518019-00687-0.

[31] Rao H S, Reddy, V S K, Ghorpade, V G. Influence of recycled coarse aggregate on punching behaviour of recycled coarse aggregate concrete slabs. Int. J. Mod. Eng. Res. 2012; 2(4):28152820.

[32] Rise N, De Brito J, Correia J R, Arruda M R T. Punching behaviour of concrete slabs incorporating coarse recycled concrete aggregates. Eng. Struct. 2015; 100:238-248.

[33] Francesconi L, Pani L, Stochino F. Punching shear strength of reinforced recycled concrete slabs. Const. Build. Mat. 2016; 127:248-263.

[34] Michaud K, Hoult N, Lotfy A, Lum P. Performance in shear of reinforced concrete slabs containing recycled concrete aggregate. Mater. and Struct. 2016; 49(10):4425-4438.

[35] Xiao J, Sun C, Jiang X. Flexural behaviour of recycled aggregate concrete graded slabs. Struct. Conc. 2015; 2:249-261.

[36] Zhou J H, Wang X B, Yu T H. Mechanic behavior test on recycled concrete simply-supported rectangular slabs. J Shenyang Jianzhu Univ Nat. Sci. 2008; 24(3):41-415 (available in Chinese).

[37] Concrete Society (CSTR 11). Concrete core testing for strength. Technical Report No.11, London, 1976; 44.

[38] BSI, BS 6089. Assessment of in-situ compressive strength in structures and precast concrete Components. BSI, London, UK, 2010.

[39] Zega C J, Di Maio A A. Recycled concrete made with different natural coarse aggregates exposed to high temperature. Constr. Build. Mat. 2009; 23:2047-52.

[40] Vieira J P B, Correia J R, De Brito J. Post-fire residual mechanical properties of concrete made with recycled concrete coarse aggregates. Cem. Conc. Res.2011; 41(5):533-541.

[41] Cree D, Green M, Noumowé A. Residual strength of concrete containing recycled materials after exposure to fire: a review. Constr. Build. Mat. 2013; 45:208-223.

[42] Kou S C, Poon C S, Etxeberria M. Residue strength, water absorption and pore size distributions of recycled aggregate concrete after exposure to elevated temperatures. Cem. Concr. Comp. 2014; 53:73-82.

[43] Dong H, Wanlin Cao W, Bian J, Zhang J. The fire resistance performance of recycled aggregate concrete columns with different concrete compressive strengths. Materials 2014; 7:78437860 .

[44] Laneyrie C, Beaucour A L, Green M F, Hebert R L, Ledesert B, Noumowe A. Influence of recycled coarse aggregates on normal and high-performance concrete subjected to elevated temperatures. Constr. Build. Mat. 2016; 111:368-378.

[45] Unal G, Demir U, Saribas I, Goksu C, Ilki A. Seismic behavior of RC columns containing sustainable concrete after exposure to elevated temperatures. To be submitted to ASCE Structural Journal. 